\title{
Aluminium alloy corrosion inhibition by pigments based on ion exchanged zeolite
}

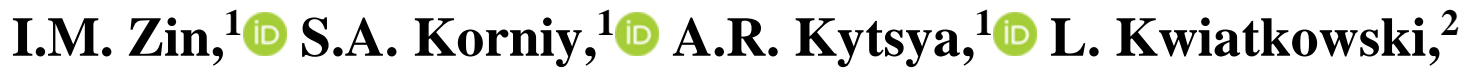 \\ P.Ya. Lyutyy ${ }^{1}\left(\mathbb{B}\right.$ and Ya.I. Zin ${ }^{1}{ }^{\circ *}$ \\ ${ }^{1}$ Karpenko Physico-Mechanical Institute, National Academy of Sciences of Ukraine, \\ 79060 Lviv, Ukraine \\ ${ }^{2}$ Institute of Precision Mechanics, Duchnicka 3, 01-796 Warsaw, Poland \\ *E-mail: ivanzin2050@gmail.com
}

\begin{abstract}
We developed a complex anti-corrosion pigment based on Ca-ion exchanged nanoporous zeolite powder with deposited zinc phosphate layer. The pigment contains composite fragments as well as individual particles of zinc phosphate. Potentiodynamic polarization studies of the D16T alloy in artificial acid rain revealed that the complex pigment is superior to commercial zinc phosphate and $\mathrm{Ca}$-ion exchanged zeolite. The complex pigment is characterized by cathodic control of aluminum alloy corrosion at the beginning, changing to anodic control after two days of exposure to the corrosion solution due to the formation of a corrosion-resistant film. It was established by electrochemical impedance spectroscopy that the pigment significantly increases charge transfer resistance of aluminium alloy surface in the vicinity of through defect in inhibited paint exposed to an acid rain solution. The anti-corrosion effectiveness of this inhibitor in the coating is higher than zinc phosphate pigment Novinox PZ02 used for alkyd systems. The phase angle frequency dependence of aluminum alloy indicates the formation of a corrosionresistant film on the metal under the defect of the coating inhibited with the complex zeolite/phosphate pigment. Ion-modified zeolites and their complex pigments with zinc phosphate are promising ecologically safe inhibiting components of paint coatings for anticorrosion protection of aluminium alloy structures under industrial atmosphere conditions.
\end{abstract}

Key words: D16T aluminium alloy, alkyd coating, inhibiting pigments, zeolite, phosphate, corrosion inhibition.

Received: February 22, 2021. Published: April 6, 2021

doi: $\underline{10.17675 / 2305-6894-2021-10-2-3}$

\section{Introduction}

Zeolites have found many practical applications [1]. These minerals belong to the group of aqueous aluminosilicates of alkali and alkaline earth metals with a tetrahedral structural framework comprising nanoscale pores occupied by cations and water molecules. A mineral from the zeolites family can be depicted as a crystalline aluminosilicate anion, which charge is compensated by cations of sodium, potassium, calcium, or magnesium. Cations and water molecules are weakly bound to the frame and can be partially or completely replaced by ion 
exchange without destruction of the zeolite frame. Zeolite deprived of water forms a crystalline "sponge" with nanopores occupying up to $50 \%$ of the mineral volume. This "sponge" with a diameter of pores from 0.3 to $1 \mathrm{~nm}$ is a promising filler for paints, ensuring their well-ordered structuring on the nanoscale level. At the same time, such properties of zeolites as the ability to ion exchange and the intercalation of their highly porous structure may be important for obtaining highly effective inhibiting pigments for organic primer coatings. It might be possible to replace the chromate-based pigments in paints by using encapsulated non-toxic corrosion inhibitors $[2,3]$.

The aim of the work was to develop complex anti-corrosion pigments based on an ionexchanged zeolite containing zinc phosphate deposit on its nanoporous surface and to study their protective action in alkyd paint coating on aluminium alloy.

\section{Modification of natural zeolite by $\mathrm{Ca}^{2+}$ ions}

The basic material for anti-corrosion pigments was natural zeolite of clinoptilolite type from the Sokyrnytsia field in the Transcarpathian region of Ukraine. Natural zeolite was dispersed in Retsch planetary ball mill PM100 to a fraction of $0.02-0.03 \mathrm{~mm}$ and washed by distilled water followed decantation and filtration. The dispersed zeolite was repeatedly washed a few times until it became slightly green in color. The cleaned zeolite was then dried for $12 \mathrm{~h}$ at $20^{\circ} \mathrm{C}$. A total of $100 \mathrm{~g}$ of the clean natural zeolite was added to $800 \mathrm{ml}$ of $0.36 \mathrm{M} \mathrm{CaCl}_{2}$ solution. The solution was stirred on a combined hot-plate magnetic-stirrer device at $70^{\circ} \mathrm{C}$ for $1 \mathrm{~h}$. The liquid was decanted after zeolite precipitation and cooling of a solution. The procedure was repeated till no more ion exchange can take place. This was determined by gravimetric measurement of free calcium and zinc ions in solutions as oxalate precipitates [4]. The Ca ion-exchanged zeolite was then filtered, washed, and dried in a vacuum chamber at $100^{\circ} \mathrm{C}$.

\section{Synthesis of complex pigment "zeolite- $\mathrm{Ca}^{2+} / \mathrm{Zn}_{3}\left(\mathrm{PO}_{4}\right)_{2}$ "}

Complex pigment "zeolite- $\mathrm{Ca}^{2+} / \mathrm{Zn}_{3}\left(\mathrm{PO}_{4}\right)_{2}$ " at a component ratio of 1:1 was synthesized using freshly prepared $\mathrm{Ca}^{2+}$ ions modified zeolite. Synthesis of the composite was carried out in a glass reactor at room temperature according to the following procedure: $5 \mathrm{~g}$ of $\mathrm{Ca}$ ion-exchanged zeolite was placed in $100 \mathrm{ml}$ of $0.33 \mathrm{M} \mathrm{Zn}\left(\mathrm{CH}_{3} \mathrm{COO}\right)_{2}$ solution, after which, at constant stirring, $35 \mathrm{ml}$ of $0.56 \mathrm{M}\left(\mathrm{NH}_{4}\right)_{3} \mathrm{PO}_{4}$ solution was added. The resulting precipitate was separated using a Büchner funnel and a Bunsen flask and dried at $120^{\circ} \mathrm{C}$. The results of SEM/EDS analysis (using EVO-40XVP/INCA Energy 350) indicate that the ratio Zn:P of the composite is close to 3:2 (Table 1). This fact suggests the formation of zinc phosphate in the reaction mixture.

The morphology of the complex zeolite/phosphate pigment was investigated using a scanning electron microscope (Figure 1). The synthesized specimens were found to be polydispersed, which may result from the polydispersity of zeolite itself. It is impossible to see individual fragments on the SEM images of the composition "zeolite- $\mathrm{Ca}^{2+} / \mathrm{Zn}_{3}\left(\mathrm{PO}_{4}\right)_{2}$ ", as well as individual particles of zinc phosphate. This observation might be explained by the 
crystallization of $\mathrm{Zn}_{3}\left(\mathrm{PO}_{4}\right)_{2}$ just on the surface and its stronger bond with zeolite particles due to the formation of a small amount of double $\mathrm{Zn}_{2} \mathrm{Ca}\left(\mathrm{PO}_{4}\right)_{2}$ phosphate at the interface of zeolite and phosphate phase.

Table 1. Chemical content of the complex pigment "zeolite- $\mathrm{Ca}^{2+} / \mathrm{Zn}_{3}\left(\mathrm{PO}_{4}\right)_{2}$ ".

\begin{tabular}{ccc}
\hline \multirow{2}{*}{ Element } & \multicolumn{2}{c}{ "Zeolite $-\mathbf{C a}^{2+} / \mathbf{Z n}_{3}\left(\mathbf{P O}_{4}\right) \mathbf{2}_{2}$ " } \\
\cline { 2 - 3 } & \% mass & \%at. \\
\hline $\mathrm{O}$ & 41.5 & 66. \\
$\mathrm{Al}$ & 3.9 & 3.7 \\
$\mathrm{Si}$ & 5.9 & 5.3 \\
$\mathrm{P}$ & 11.6 & 9.6 \\
$\mathrm{Ca}$ & 2.2 & 1.4 \\
$\mathrm{Zn}$ & 34.9 & 13.6 \\
\hline
\end{tabular}

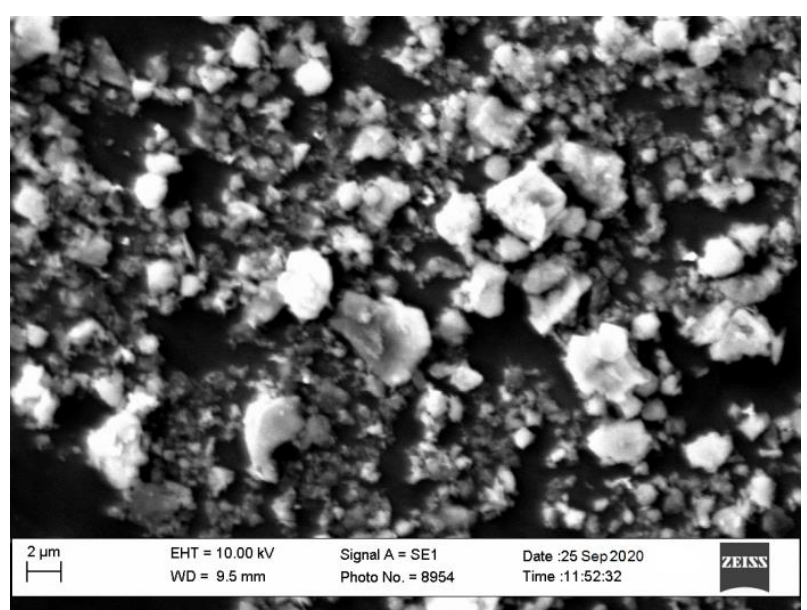

a)

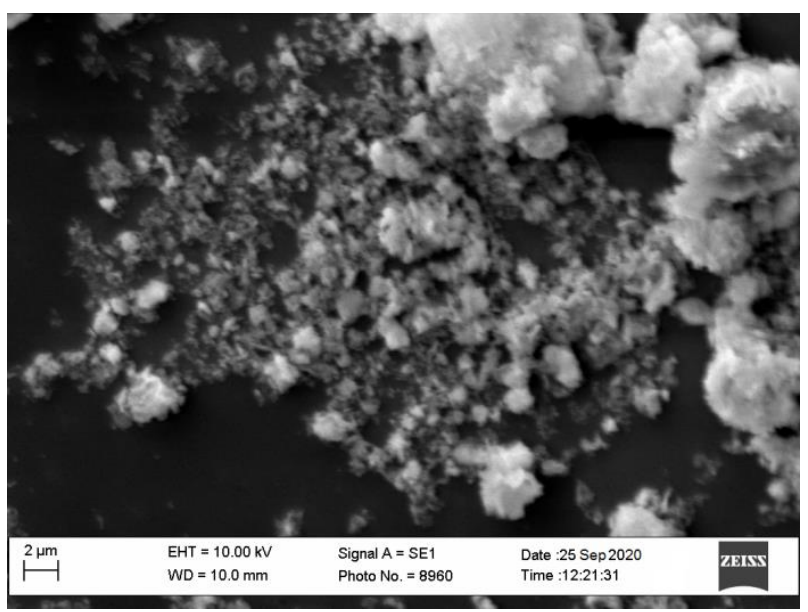

b)

Figure 1. SEM images of zeolite pigments: $a$ ) unmodified zeolite; $b$ ) complex pigment ,zeolite- $\mathrm{Ca}^{2+} / \mathrm{Zn}_{3}\left(\mathrm{PO}_{4}\right){ }_{2}$.

To determine the phase composition of synthesized complex pigment, X-ray diffraction analysis using diffractometer DRON-3.0 was carried out (Figure 2). Comparison of diffractograms shows that the positions of peaks for zeolite- $\mathrm{Ca}^{2+}$ and zeolite$\mathrm{Ca}^{2+} / \mathrm{Zn}_{3}\left(\mathrm{PO}_{4}\right)_{2}$ samples practically coincide, although the intensity of the halo in the $2 \theta$ region of $10-30^{\circ}$ increases. This fact indicates a presence of an amorphous phase. At the same time, the diffractogram does not have peaks, which are characteristic of crystalline zinc phosphate. Therefore, taking into account the data of the elemental analysis and the SEM images of the sample "zeolite- $\mathrm{Ca}^{2+} / \mathrm{Zn}_{3}\left(\mathrm{PO}_{4}\right)_{2}$ ", it can be concluded that the formed composite contains zinc phosphate in a subcrystalline or amorphous state. 


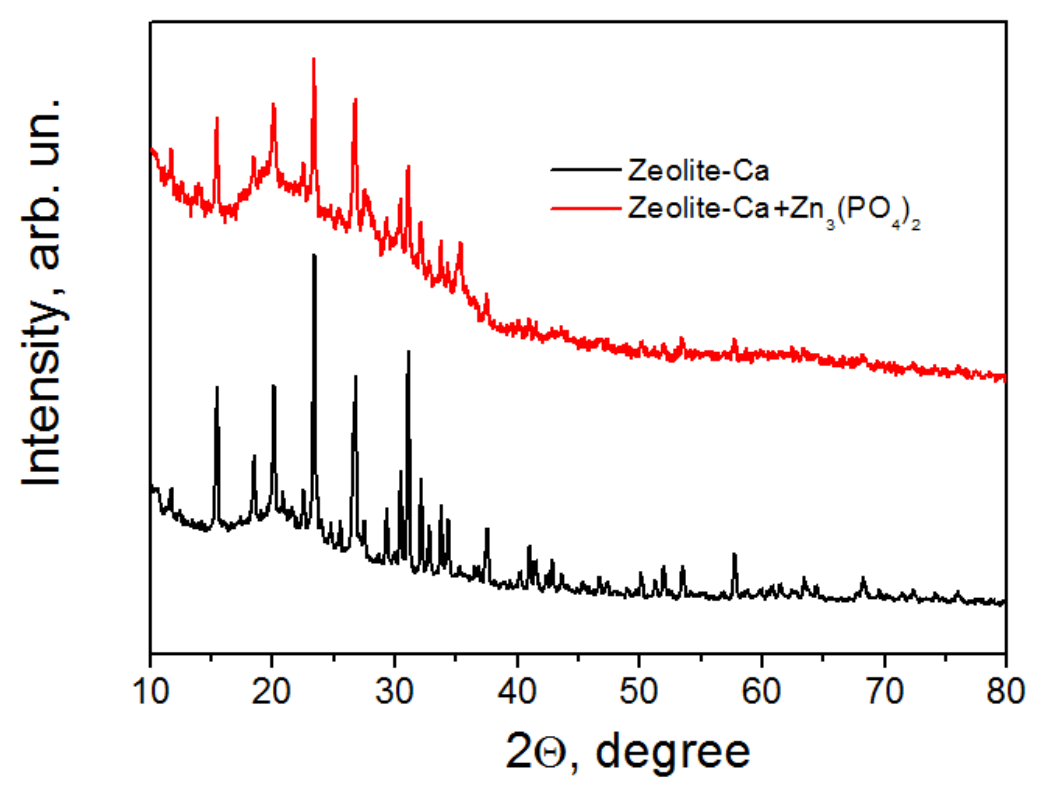

Figure 2. Diffractograms of zeolite $-\mathrm{Ca}^{2+}$ and zeolite $-\mathrm{Ca}^{2+} / \mathrm{Zn}_{3}\left(\mathrm{PO}_{4}\right)_{2}$ samples.

\section{Electrochemical methods}

Corrosion inhibition of D16T aluminium alloy by complex zeolite/phosphate pigment was studied by DC potentiodynamic polarization method. For this purpose, suspensions of zinc phosphate Novinox PZ02 and Ca-modified zeolite/zinc phosphate pigment in artificial acid rain [5] (Table 2) were prepared. The concentration of an inhibiting component in each suspension was $1000 \mathrm{ppm}$. The samples of aluminum alloy with a working area of $1 \mathrm{~cm}^{2}$ were dipped into inhibited acid rain solution, and their polarization characteristics were recorded by a Gill $\mathrm{AC}$ potentiostat using a saturated $\mathrm{Ag} / \mathrm{AgCl}$ reference electrode and a counter platinum electrode. The potential scan rate during potentiodynamic polarization was $1 \mathrm{mV} / \mathrm{s}$. The polarization tests were repeated at least three times for each sample until all runs exhibited similar polarization curves. A new alloy sample was used each time.

Table 2. The composition of artificial acid rain $(\mathrm{pH}=4.5)$.

\section{Artificial acid rain}

$\mathrm{pH}$ was adjusted to 4.5 by adding $\mathrm{Na}_{2} \mathrm{CO}_{3}$

\section{Components}

$\mathrm{H}_{2} \mathrm{SO}_{4}(98 \%)$

$\left(\mathrm{NH}_{4}\right)_{2} \mathrm{SO}_{4}$

$\mathrm{Na}_{2} \mathrm{SO}_{4}$

$\mathrm{HNO}_{3}(70 \%)$

$\mathrm{NaNO}_{3}$

$\mathrm{NaCl}$
Concentration, ppm by eight
3.185

4.620

3.195

1.575

2.125

8.483 
Protective properties of alkyd PF-170 coatings inhibited by new complex zeolite/phosphate and conventional phosphate pigments were studied by electrochemical impedance spectroscopy (EIS) widely used in corrosion research [6]. The organic coatings were applied on aluminium alloy plates in two layers by using an applicator. Inhibited alkyd compositions were used for the primer layer and the clear lacquer PF170 for the top layer. Coatings were dried at $20^{\circ} \mathrm{C}$ for 7 days. The total thickness of alkyd coatings was 120 $130 \mu \mathrm{m}$. The samples were damaged intentionally by drilling holes of $1 \mathrm{~mm}$ diameter in the coating to expose the underlying substrate and to reveal the effect of inhibitors on its underfilm corrosion. The measurements were carried out close to corrosion potential by using Gill AC potentiostat, a plexiglass tube cell attached to the surface of the sample, a saturated $\mathrm{Ag} / \mathrm{AgCl}$ reference electrode, and a platinum auxiliary electrode in the current frequency range from $1 \mathrm{kHz}$ to $0.01 \mathrm{~Hz}$ and with the signal amplitude of $10 \mathrm{mV}$. The working area of the samples was $1.75 \mathrm{~cm}^{2}$. Electrochemical impedance spectra were modeled with EIS Spectrum Analyser software [7].

\section{Protective properties of complex zeolite/phosphate pigment}

Potentiodynamic polarization studies of the D16T alloy in acid rain pigments suspensions revealed (Figure 3) that the complex pigment "zeolite- $\mathrm{Ca}^{2+} / \mathrm{Zn}_{3}\left(\mathrm{PO}_{4}\right)_{2}$ " is superior to commercial zinc phosphate pigment Novinox PZ02 and zeolite-Ca ${ }^{2+}$, taken separately. Corrosion of the aluminum alloy in the suspension of the complex pigment is significantly reduced compared to the uninhibited acid rain solution (Table 3). The complex pigment is characterized by cathodic control of corrosion of aluminum alloy at the beginning of the corrosion process, changing to anodic control while immersed in a corrosive solution. It indicates the formation of a corrosion-resistant film.

Table 3. Electrochemical parameters $\left(I_{\mathrm{cor}}, E_{\mathrm{cor}}\right)$ determined from polarization curves.

\begin{tabular}{ccccc}
\hline \multirow{2}{*}{$\begin{array}{c}\text { Time, } \\
\text { hours }\end{array}$} & \multicolumn{4}{c}{ Corrosion current, $\boldsymbol{\mu A} / \mathbf{c m}^{2}$} \\
\cline { 2 - 5 } & uninhibited & Ca-zeolite & Zinc phosphate & Ca-zeolite/zinc phosphate \\
\hline 3 & 0.7 & 0.4 & 0.4 & 0.3 \\
24 & 0.7 & 0.7 & 0.4 & 0.04 \\
\hline \multirow{2}{*}{ Time, } & \multicolumn{5}{c}{ Corrosion potential, $\mathbf{~ W V}$} \\
\cline { 2 - 5 } hours & uninhibited & Ca-zeolite & Zinc phosphate & Ca-zeolite/zinc phosphate \\
\hline 3 & -410 & -430 & -435 & -740 \\
24 & -415 & -440 & -460 & -555 \\
\hline
\end{tabular}



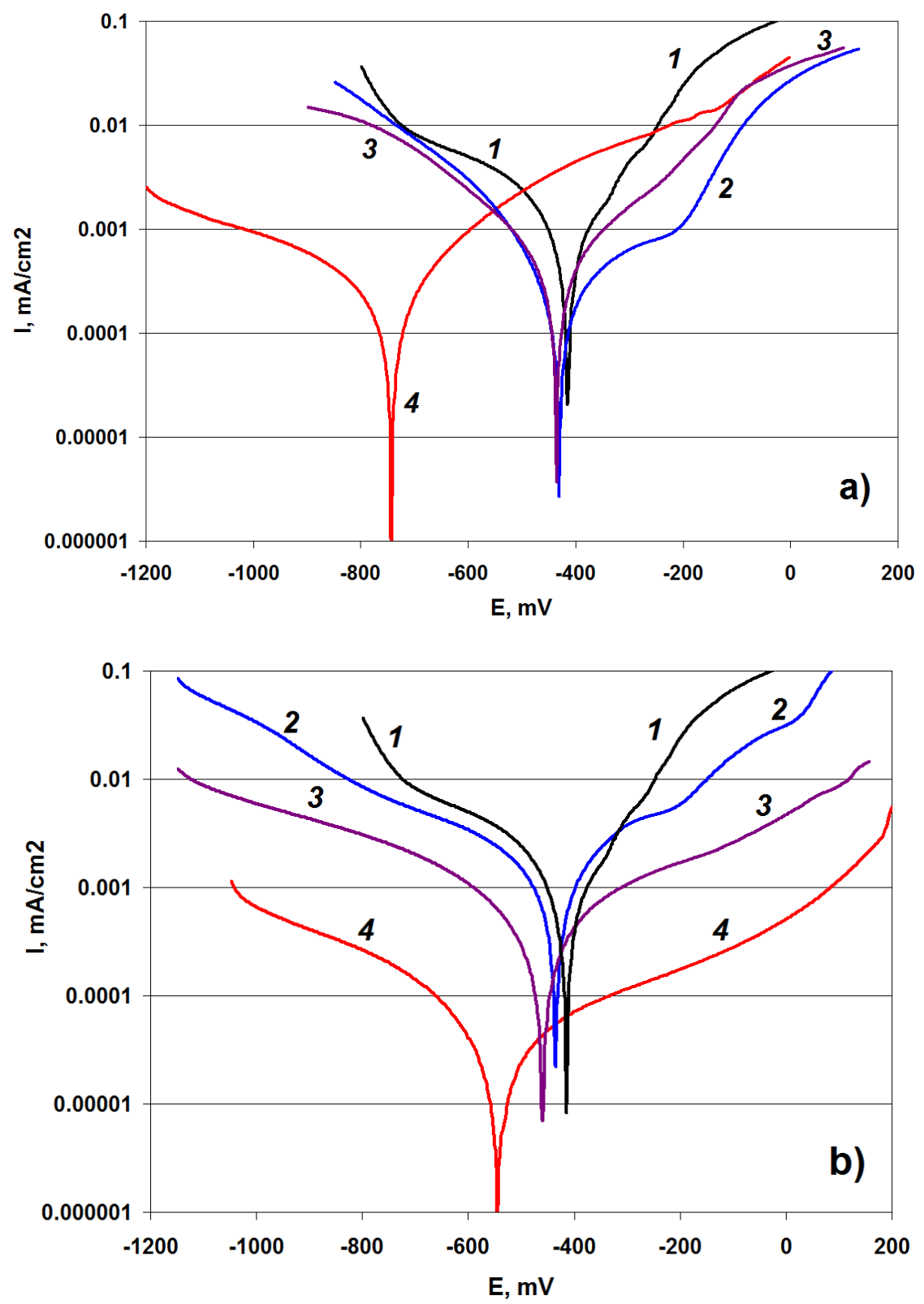

Figure 3. Potentiodynamic polarization curves of D16T aluminium alloy after 3 (a) and 48 hours (b) exposure in acid rain solution: 1 - uninhibited, 2 - suspension with Ca-zeolite, 3 suspension with phosphate Novinox PZ02, 4 - suspension with complex pigment Ca-zeolite/ zinc phosphate.

Alkyd coatings were applied in two layers on flat samples of D16T aluminum alloy. The complex pigment zeolite- $\mathrm{Ca}^{2+} / \mathrm{Zn}_{3}\left(\mathrm{PO}_{4}\right)_{2}$ and zinc phosphate pigment were introduced into an alkyd lacquer PF-170 in an amount of 3 vol.\%. The first primer layer contained inhibiting pigments and the second layer was applied without inhibitors. Defects with a diameter of $1 \mathrm{~mm}$ were made in alkyd coatings to simulate the damage situation and the development of underfilm corrosion. The solution simulating acid rain was used as a corrosive environment (Table 2). For comparison, an alkyd coating with zinc phosphate Novinox PZO2 was used as a reference pigment in this study. Complex zeolite/zinc 
phosphate pigment slows down the development of underfilm corrosion of an aluminum alloy with the alkyd coating, as evidenced by the change of charge transfer resistance of aluminum alloy-electrolytic solution interface. The calculation of impedance parameters of alloy samples with inhibited coatings was conducted using EIS Analysis software [7] and an equivalent electric circuit $R_{\mathrm{e}}\left(R_{\mathrm{ct}} \cdot Q_{\mathrm{dl}}\right)$, where $R_{\mathrm{e}}$ is the resistance of the electrolyte, $R_{\mathrm{ct}}$ is the aluminum alloy charge transfer resistance, $Q_{\mathrm{dl}}$ is the capacity of the double layer expressed through the constant phase element. It was determined that the charge transfer resistance of the alloy samples with uninhibited alkyd coating is about $2.7 \cdot 10^{4} \Omega \cdot \mathrm{cm}^{2}$. The resistance increases with addition to the coating of Ca-zeolite and zinc phosphate to $1.2 \cdot 10^{5} \Omega \cdot \mathrm{cm}^{2}$ and $1.45 \cdot 10^{4} \Omega \cdot \mathrm{cm}^{2}$, respectively, and reaches the maximum value of $2.2 \cdot 10^{5} \Omega \cdot \mathrm{cm}^{2}$ in case of using complex zeolite/phosphate pigment (Figure 4). It is concluded that the effectiveness of this inhibitor in the coating is higher than that of the commercial zinc phosphate pigment Novinox PZ02, which is organically modified to be more reactive than standard zinc phosphate for alkyd systems. The organic activator provides a higher solubility of the pigment in the initial stages of corrosion leading to a higher reactivity and protection [8]. The phase angle frequency dependence of aluminum alloy indicates the formation of a corrosion-resistant film on the metal under the defect of the coating in the presence of a complex zeolite/phosphate pigment (Figure 4, curve 4). In this case, the phase angle maximum of $\mathrm{AC}$ frequency dependence is situated at $10 \mathrm{~Hz}$, while for other coatings - in the range of $0.6-2 \mathrm{~Hz}$. In $[9,10]$, the shift of the maximum towards higher frequencies is explained by a protective film formation on the metal surface in inhibited corrosion solution.

The anti-corrosion effect of the synthesized complex pigment can be explained as follows:

1. The formation of a zinc phosphate layer on a nanoporous zeolite surface leads to an increase in the solubility of $\mathrm{Zn}_{3}\left(\mathrm{PO}_{4}\right)_{2}$ in water and, accordingly, to a higher concentration of $\mathrm{Zn}^{2+}$ and $\mathrm{PO}_{4}^{3-}$ in the solution.

2. Zeolites are natural minerals with an open frame structure of the type $\left[(\mathrm{Si}, \mathrm{Al}) \mathrm{O}_{4}\right]$, which has a negative charge. Such a charge can be compensated by positively charged ions of metals, which causes a high cation exchangeability of zeolites. Thus, zeolites, which negative charge is compensated by calcium ions, will take part in corrosion inhibition by the additional release of $\mathrm{Ca}^{2+}$ during the corrosion process of aluminium alloy.

3. In case of using a composite consisting of natural zeolite modified with calcium ions and zinc phosphate deposited on its surface, a synergistic effect could be observed, as there is a simultaneous release of calcium ions from zeolite and the dissolution of zinc phosphate. As a result, the formation of a zinc phosphate protective film, modified with calcium ions, is possible on the surface of the metal under paint defect [11].

4. The SEM study of zeolite- $-\mathrm{Ca}^{2+} / \mathrm{Zn}_{3}\left(\mathrm{PO}_{4}\right)_{2}$ and a comparison of the data from EDS and $\mathrm{X}$-ray diffraction analyses indicate that zinc phosphate dispersion in the composite is high. Accordingly, the solubility of $\mathrm{Zn}_{3}\left(\mathrm{PO}_{4}\right)_{2}$ may increase. For example, if we assume that the zinc phosphate nanoparticle size is about $50 \mathrm{~nm}$, then the $\mathrm{Zn}_{3}\left(\mathrm{PO}_{4}\right)_{2}$ solubility product 
(SP) increases by 180 times, and with a particle size of about $10 \mathrm{~nm}, \mathrm{SP}\left(\mathrm{Zn}_{3}\left(\mathrm{PO}_{4}\right)_{2}\right)$ $1 \cdot 10^{-23}$, which is $10^{9}$ times higher than for particles of micron size.
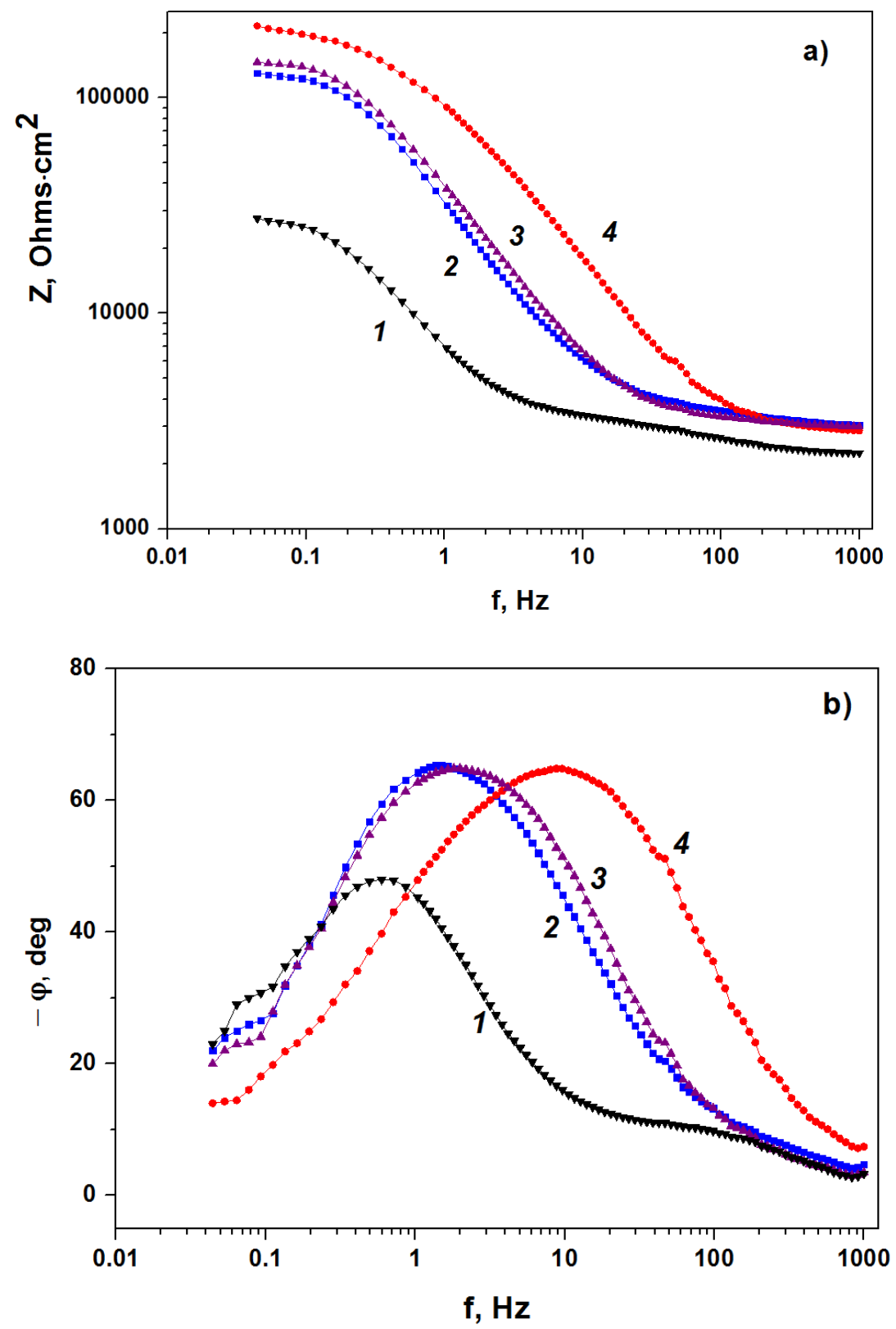

Figure 4. Frequency dependencies of impedance modulus (a) and phase angle (b) of aluminium alloy with alkyd coatings after 48 hours exposure in acid rain solution: 1 coating without pigment, 2 - coating with 3 vol.\% of Ca-zeolite, 3 - coating with 3 vol.\% of zinc phosphate, 4 - coating with 3 vol.\% of complex pigment Ca-zeolite/zinc phosphate.

The possible mechanism of aluminium alloy corrosion inhibition in the presence of the zeolite-Ca ${ }^{2+} / \mathrm{Zn}_{3}\left(\mathrm{PO}_{4}\right)_{2}$ composite in acid rain is depicted in Figure 5. 


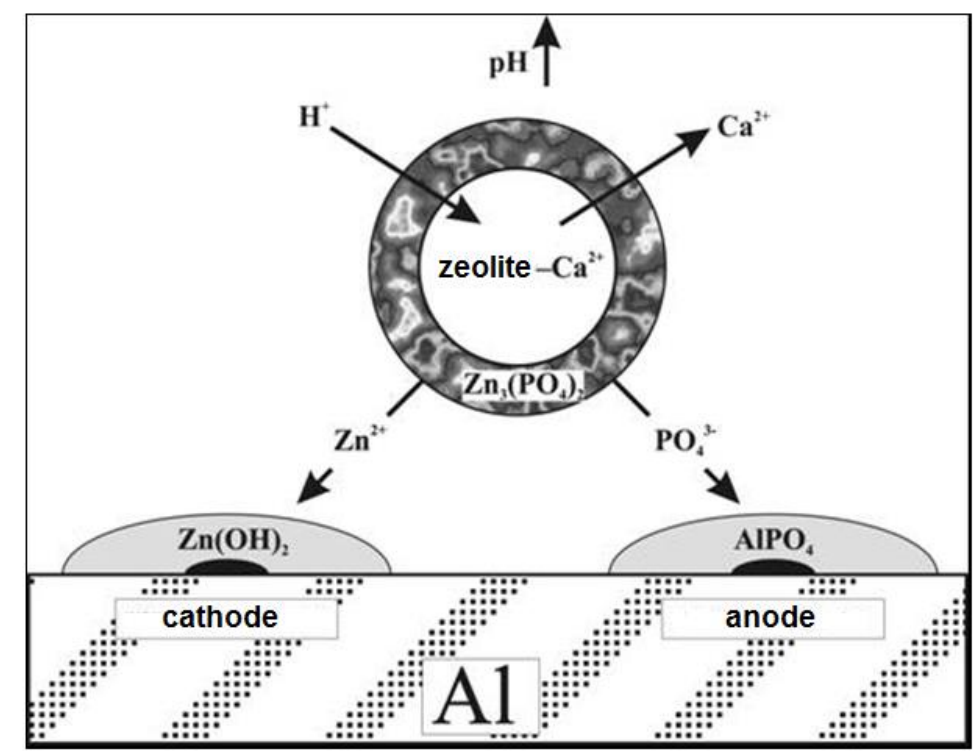

Figure 5. Scheme of protective action of complex Ca-zeolite/zinc phosphate pigment on aluminium alloy.

\section{Conclusions}

We obtained an ion exchanged $\mathrm{Ca}$ (II) zeolite with the following deposition on its nanoporous surface of amorphous zinc phosphate. It was found that the zeolite/zinc phosphate pigment can effectively inhibit the corrosion of an aluminum alloy in synthetic acid rain. Its application reduces the corrosion current of aluminum alloy in acid rain by up to 17 times. It is effective in suppressing underfilm corrosion of aluminum alloy in the vicinity of alkyd coating defects. The results of the study show that ion-modified zeolites and their complex pigments with zinc phosphate may become promising ecologically safe inhibiting components of paint coatings for protection of constructions with aluminum alloys under industrial atmosphere conditions.

The work was performed within the project No. 2020.02/0063 "Synthesis and properties of new complex anti-corrosion pigments for paint coatings based on aluminosilicate nanocontainers" of the National Research Foundation of Ukraine.

\section{References}

1. S.M. Auerbach, K.A. Carrado and P.K. Dutta, Handbook of Zeolite Science and Technology, 2003, p. 1170. doi: 10.1201/9780203911167

2. Yu.I. Kuznetsov, Progress in the science of corrosion inhibitors, Int. J. Corros. Scale Inhib., 2015, 4, no. 1, 15-34. doi: 10.17675/2305-6894-2015-4-1-015-034

3. V.A. Golovin and S.A. Tyurina, Microencapsulation of corrosion inhibitors and active additives for anticorrosive protective polymer coatings, Int. J. Corros. Scale Inhib., 2019, 8, no. 2, 179-198. doi: 10.17675/2305-6894-2019-8-2-2

4. Methods of Analysis of Brines and Salts, Eds. Yu.V. Morachevski and E.M. Petrova, Moscow-Leningrad, Khimiya, 1964, p. 405 (in Russian). 
5. S.J. Haneef, C. Dickinson, J.B. Johnson, G.E. Thompson and G. C. Wood, Simulation of the degradation of coupled stones by artificial acid rain, Stud. Conserv., 1992, 37, 105-112. doi: $10.1179 /$ sic.1992.37.2.105

6. V.A. Golovin, S.A. Dobriyan and V.E. Kasatkin, Electrochemical impedance spectroscopy (EIS) of composite polymer coatings on metal substrates, Int. J. Corros. Scale Inhib., 2018, 7, no. 4, 697-709. doi: 10.17675/2305-6894-2018-7-4-15

7. A.S. Bondarenko and G.A. Ragoisha, EIS Spectrum Analyser (analysis and simulation of impedance spectra). http://www.abc.chemistry.bsu.by/vi/analyser/

8. http://www.sncz.com/images/upload/1016-v0-03-novinox-pz02-0516g-english.pdf

9. S. Puelles, M. Ghorbani, R. Yunis, L.L. Machuca, H. Terryn, M. Forsyth and A.E. Somers, Electrochemical and surface characterization study on the corrosion inhibition of mild steel 1030 by the cationic surfactant cetrimonium trans-4-hydroxycinnamate, ACS Omega, 2021, 6, 1941-1952. doi: 10.1021/acsomega.0c04733

10. H. Duan, K. Du, C. Yan and F. Wang, Electrochemical corrosion behavior of composite coatings of sealed MAO film on magnesium alloy AZ91D, Electrochim. Acta, 2006, 51, 2898-2908. doi: $10.1016 /$ j.electacta.2005.08.026

11. I.M. Zin, S.B. Lyon, V.I. Pokhmurskii, M.C. Simmonds, Inhibition of steel and galvanized steel corrosion by zinc and calcium ions in the presence of phosphate, Corros. Eng., Sci. Technol., 2004, 39, 167-173. doi: 10.1179/147842204225016967 